\title{
Las tres llaves y Los huevos sin sal: Versiones hispanocristianas y sefardíes de dos ensalmos mágicos tradicionales
}

José Manuel PEDROSA

Universidad de Alcalá de Henares, Madrid

\section{LAS TRES LLAVES EN LA TRADICIÓN ESPAÑOLA}

Una de las oraciones piadosas más difundidas en la tradición folclórica de España y de Hispanoamérica es la de La candela nocturna. Tal oración, a algunos de cuyos motivos poéticos he dedicado un estudio ${ }^{1}$, es una de las que nos han revelado, en los últimos tiempos, estrechos e inesperados vínculos formulísticos entre el repertorio religioso tradicional hispanocristiano y el judío sefardí ${ }^{2}$. En mi estudio citado, me he centrado sólo en unos cuantos elementos de su poética, aplazando el análisis de

1 J. M. PEDROSA, «La candela nocturna: canción de alba sefardí, oración cristiana panhispánica y canción piadosa del Siglo de Oro», en prensa para Studia Neophilologica.

${ }^{2}$ Las coincidencias entre ambos repertorios fueron puestas por primera vez de relieve por Samuel G. Armistead y Joseph H. Silverman, «A Judeo-Spanish Prayer», La Coronica 19 (1990/1991) págs. 22-31. Posteriormente he dedicado los siguientes trabajos a la misma cuestión: «Conjuros y ritos mágicos sobre la dentición infantil», Revista de Dialectología y Tradiciones Populares 48 (1993) págs. 155-167; «Vida oral y recreación poética de la canción de Las tres palomas / Les tres palometes», Fulls de Treball de Carrutxa 2 (1994) págs. 77-88; «Correspondencias cristianas y judías de la oración de Las cuatro esquinas», en mi libro Las dos sirenas y otros estudios de literatura tradicional (De la Edad Media al siglo XX) (Madrid 1995) págs. 187-220; y «La pizarra latina de Carrio (siglo VIII) y la cuestión de orígenes de la poesía tradicional románica y europea», en Actas del Sexto Congreso Internacional de la Asociación Hispánica de Literatura Medieval (Alcalá de Henares, septiembre de 1995), ed. J. M. LucíA Megías, 2 vols. (Alcalá de Henares 1997) vol. II págs. 1.147-1.158. 
otros -que en aquel trabajo tenían interés periférico- para una ocasión posterior.

Es el momento, pues, de recuperar una versión de La candela nocturna que nos permita reorientar nuestro análisis. Fijémonos en el siguiente texto tradicional que recogí en 1989 en el pueblo de La Nava de Francia (Salamanca). Vale la pena llamar la atención sobre algunos de sus últimos versos, los que dicen que María «tiene tres llaves: / con una cierra, / con otra abre, / con otra dice / el Ave María y la Salve», porque van a ser uno de los objetos de atención central de este estudio:

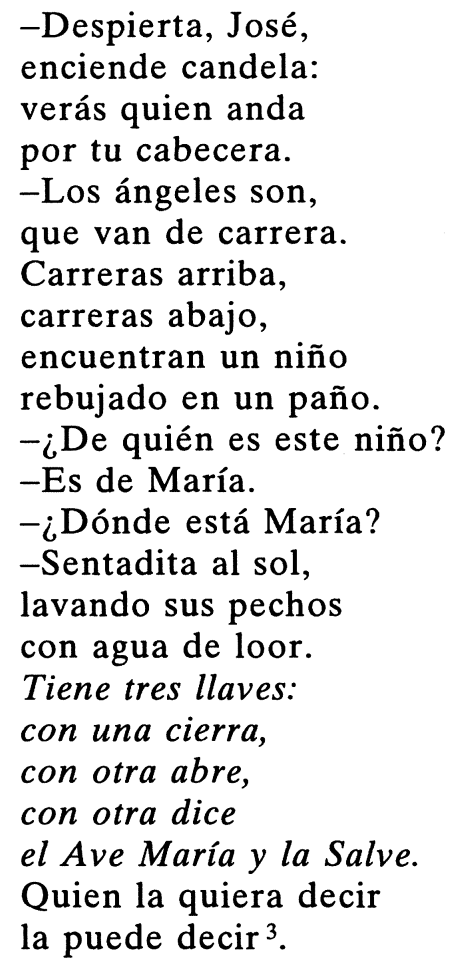

Ese motivo de Las tres llaves se inserta en un número proporcionalmente muy escaso de versiones españolas de la misma

${ }^{3}$ La informante fue la señora Ricarda, de 95 años, entrevistada en su pueblo el 31 de julio de 1989, en la encuesta que realicé junto con José María Sanz y José Luis González. 
oración de La candela nocturna. Una de ellas, recogida en Guijo de Santa Bárbara (Cáceres), presenta los siguientes versos de cierre:

\author{
Y lleva tres llaves: \\ con una se cierra, \\ con otra se abre, \\ con otra se dice \\ el Credo y la Salve 4 .
}

Y también aparece en otra versión de Casares de Arbas (León):
$Y$ llevan tres llaves
de oro en la mano:
con una se cierra.
con otra se abre,
con otra se reza
el Credo y la Salves.

Otra oración, distinta de la de La candela nocturna, pero que incluye el mismo tópico formulístico, es la siguiente, que recogí en el pueblo de Espinareda de Ancares (León):

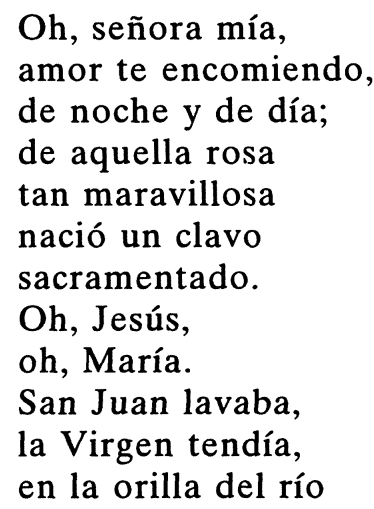

4 A la informante, Isabel Vasco, nacida en Guijo de Santa Bárbara en 1940 la entrevisté en Madrid el 12 de julio de 1991.

5 A la informante Nieves Rodríguez Cañón, nacida en 1937, la entrevisté el 1 de octubre de 1991 en encuesta realizada junto con María José Sanz. 


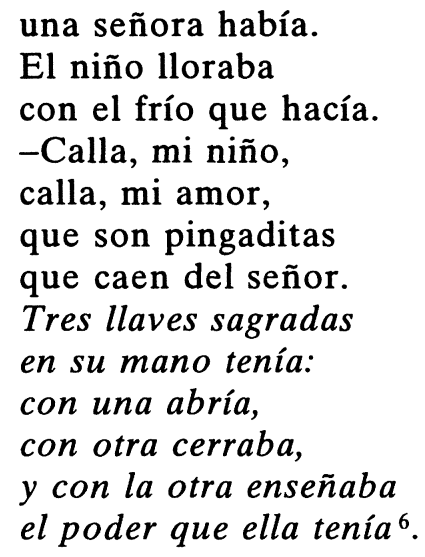

Una última oración que incluye el raro tópico de Las tres llaves es la siguiente, recogida de la tradición asturiana:

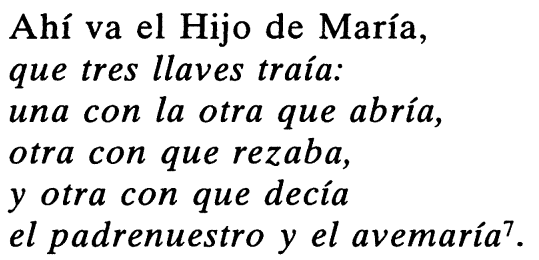

\section{LAS TRES LLAVES EN LA TRADICIÓN SEFARDÍ}

Entre varios millares de oraciones registradas y cotejadas, esos cinco ejemplos hispanos peninsulares constituyen todo el corpus que he podido allegar de versiones ibéricas de Las tres llaves. Su escaso número no es, sin embargo, obstáculo para permitirnos la comparación con el mismo tópico que se da en algunas versiones del percante, precante, precantar o aprecan$\operatorname{tar}^{8}$ sefardí contra el mal de ojo, es decir, del ensalmo usado

\footnotetext{
${ }^{6} \mathrm{La}$ informante fue Rosa Abella, de 68 años, a quien entrevisté en su pueblo el día 16 de julio de 1993.

7 José Manuel Ferto, «Devocionario popular (zona de Somiedo)», Boletín del Instituto de Estudios Asturianos 45/137 (1991) págs. 7-86: pág. 62.

${ }^{8}$ La etimología de todas estas designaciones populares de los ensalmos que los sefardíes suelen emplear en los tratamientos de diversas enfermedades nunca se ha explicado de manera convincente. Aunque resulta obvio el parentesco con la familia de la voz encanto (y con en-cantar), la anteposición del prefijo
} 
por los sefardíes de Oriente para intentar curar esa supuesta enfermedad ${ }^{9}$.

Los dos primeros textos conocidos del ensalmo sefardí los publicó Abraham Galanté en 1935 y 1937. Por desgracia, no lo hizo en su lengua original, sino en traducciones francesas muy problemáticas desde el punto de vista filológico, ya que, aunque advertía que una procedía de Rodas y la otra de Esmirna, su absoluta identidad delata su unidad de origen. Del primer texto explicó Galanté que, mientras la aprecantadera lo leía o recitaba, agitaba la palma de la mano, que guardaba un poco de sal, en torno a la cara y a la cabeza del enfermo. Al finalizar el conjuro, echaba la sal en un recipiente, se lavaba las manos, y hacía lavar la cara al paciente diciendo «todo el mal a la mar». Casi al final del conjuro, que traduzco del francés al español, se apreciará la nueva alusión a Las tres llaves:

En el nombre del Dios de Abraham, de Isaac, de Jacob, de David y de Salomón, yo pongo la mano y Dios los buenos resultados. He encontrado al pasearme un viejecito vestido y calzado de hierro, que se llamaba José el Justo. «¿Dónde vas?». "A casa de tal, hijo de tal, o a casa de tal, hija de tal». De la misma forma que no se pueden contar las estrellas, ni medir la mar, ni abrazar las montañas, que no tengan este niño o esta niña ningún mal. Si el mal de ojo proviene de una viuda, que pierda la vista; si viene de una muchacha, que pierda el honor; si viene de un joven, que se funda como el sebo; si viene de una casada, que pierda su reputación; si viene de una no judía, que se disuelva como la sal; si viene de un pájaro mudo, que el Dios de Abraham venga en su ayuda. Al pasearme, he encontrado a un joven que tenía tres llaves de oro en su mano. Con una abría, con otra cerraba y con la otra

per- o pre- en el ámbito sefardí no tiene paralelos en el resto de las lenguas y dialectos ibéricos. Las menciones y eventuales comentarios en los trabajos de Wiener, Wagner, Crews y Sala citados en Elena Romero, El teatro de los sefardíes orientales (Madrid 1979) vol. III pág. 1289, s.v. precante, no han podido, en consecuencia, establecer una etimología ni una línea evolutiva segura de este complejo de voces.

${ }_{9}$ Sobre esta patología, más cultural que clínica, basada en la creencia de que la mirada de determinadas personas puede ser perjudicial e inducir enfermedades en otras personas o animales, hay una muy amplia bibliografía mundial, entre la que merece la pena citar The Evil Eye: A Folklore Casebook, ed. A. DuNDEs (Wisconsin 1981), y Anton Erkoreka, Begizkoa: Mal de ojo (Bilbao 1995). Ambas obras incluyen bibliografías exhaustivas sobre la cuestión. 
el mal de ojo quitaba [y decía]: "Yo te quito el mal de ojo, yo te quito el mal de ojo, yo te quito la palabra mala [que otros han dicho contra el enfermo] y toda clase de mal»: y todo lo echo a la profundidad de la mar, [para] que este muchacho o esta muchacha no tengan ningún mal. Que el mal de ojo se vaya por allí o por allá comiendo huevos sin sal ${ }^{10}$.

Otro de los textos conocidos desde más antiguo del aprecantar sefardí contra el mal de ojo es el que incluyó Albert Adatto en un trabajo fechado en 1939 sobre la literatura tradicional de los sefardíes de Oriente establecidos en la ciudad norteamericana de Atlanta. Este autor informó de que su recitadora lo pronunciaba al tiempo de agitar su mano, que apretaba quince clavos, sobre la cabeza y los hombros del enfermo. Al finalizar el aprecantar, los clavos eran arrojados al fuego: si restallaban y chispeaban, ello era señal de la afección del mal de ojo; si no lo hacían, era señal de que la enfermedad tenía poca importancia. He aquí su comienzo:

Adio el alto melizina

para tu daño.

Yo quito mi mano,

el Dio mete la suya.

Tres yaves de oro tenía:

con la una avria,

con la otra serava,

y con la otra el mal kitava ${ }^{11}$.

El siguiente texto es el inicio de una versión del aprecantar recordada en 1984 por una mujer sefardí de Esmirna:

Caminando por un caminico encontrí a un viejićico.

Fierro vistía, fierro calzaba, armas de fierro llevaba.

10 Abraham Galanté, Histoire des Juifs de Rhodes, Chio, Cos, etc. (Istambul 1935) cap. XXIV: «Superstitions» pág. 119; la otra versión del ensalmo, idéntica a la de Rodas, está publicada en Histoire des Juifs d'Anatolie: Les Juifs d'Izmir (Smyrne) (Istambul 1937) cap. XXXII: «Superstitions» págs. 260-261.

11 Albert Adatro, Sephardim and the Seattle Sephardic Community (tesis inédita, Washington 1939) pág. 157. 
Tres llaves tinía:

una abría,

una cerraba,

y todo modo de mal

al dip de la mar echaba ${ }^{12}$.

Conocemos otros dos textos fragmentarios de la isla de Rodas. El primero:

Caminando, caminando,

me encontré con señor Yosef Hasadiq:

de oro vestía y de seda calzaba,

treśllaves de oro en su mano llevaba:

con una abría y con otra cerraba

y con otra el ayin hará le quitaba ${ }^{13}$;

y el segundo:

Por un kaminiku pasi,

kun un viejiziku 'skontri,

al i vedri vistia,

tres yavizikas tenia en su mano,

una d'avrir, una di sirar, una di kitar todu il mal ${ }^{14}$.

La funcionalidad como fórmulas mágicas y piadosas en ambas tradiciones y las similitudes formulísticas entre los testimonios españoles y sefardíes (que a veces llegan a descender hasta el detalle de que las tres llaves eran «de oro» ${ }^{15}$ ), avalan una indiscutible relación genética entre ambas ramas.

LA MAGIA DE LAS TRES LLAVES

Es bien conocida la nutrida bibliografía internacional sobre los valores y el carácter mágico-supersticioso que en muchas

${ }^{12}$ La informante fue Djoya Sasson, originaria de Esmirna y entrevistada en 1984 por Matilda Koen-Sarano. Agradezco a Moshé Shaul el envío y cesión del texto escrito (cuya ortografía he normalizado). Dip tc. 'fondo'.

13 Susana WeIch-SHAHAK, Música y tradiciones sefardies (Salamanca 1992) pág. 34. Hasadiq hb. hasadic 'el justo'; 'ayin hará' hb. 'mal de ojo'.

${ }_{14}$ Isaac Jack LÉVY, con la colaboración de Rosemary LÉvY ZuMwalT, «Prekantes: kuras majikas entre los sefaradis del Imperio Otomano», Aki Yerushalayim 18:55 (1997) págs. 42-45. Al tc. 'rojo'.

15 Compárense los textos citados de León (supra y nota 5) y de Oriente (supra y notas 11 y 13). 
culturas se atribuye al número tres, y su aparición en una abundantísima literatura tanto culta como tradicional y en todo tipo de poemas mágicos, religiosos, épicos, líricos y baladísticos universales ${ }^{16}$.

Conviene pues que pasemos, sin más dilación, a analizar el papel simbólico de las (tres) llaves en nuestro conjuro y, en general, en la tradición religiosa y supersticiosa popular, con el fin de comprender mejor su sentido en los textos que estamos analizando.

En principio, se podría aventurar que las tres llaves de nuestros ensalmos podrían evocar las llaves del Paraíso que son citadas en un cierto número de oraciones cristianas, custodiadas normalmente por San Pedro o por el Niño Jesús, como muestra el siguiente ejemplo portugués:

\section{Padre-Nosso Pequenino tem as chaves do Paraiso ${ }^{17}$.}

Pero, en realidad, el simbolismo de la llave excede con mucho del ámbito cristiano para relacionarse con las amplias propiedades mágicas que en diversas culturas se le atribuyen. Sabemos que estos objetos tenían ya la consideración de fetiches mágicos entre los pueblos que habitaban al norte del antiguo Imperio Romano ${ }^{18}$. En otras culturas, cristianas y no cris-

${ }^{16}$ Sobre la recurrencia del número tres en el folclore mágico, supersticioso y medicinal véase la bibliografía que recojo en mi artículo «Las tres hilanderas: fórmula y mito en oraciones y ensalmos hispánicos y paneuropeos», en prensa para Brigantia. Sobre ensalmos y oraciones plagados de conceptos triples o de fórmulas trimembres, recordemos la parodia que de ellos hizo Cristóbal de Villalón en El Crotalón (segundo cuarto del siglo XVI):

Pues mira, hermana, que este pecado se ha de absolver con tres signos y tres cruces y tres psalmos y tres misas solenes, las cuales se han de dezir en el templo del Santo Sepulcro de Hierusalén, y que son misas de mucha costa y trabajo, porque las han de dezir tres cardenales y revestirse con ellos al altar tres obispos, $y$ hanlas de offiçiar tres patriarcas vestidos de pontifical, y han de arder allí tres çirios a cada misa. (Ed. A. Rallo [Madrid 1990] pág. 147.)

17 Flávio GonçALvES, «Orações populares de Silvares (Fundão-Beira Baixa)», Douro Litoral: Boletim da Comissão de Etnografia e História $7^{\text {a }}$ serie (1956) págs. 749-767: pág. 754. Sobre esta oración, puede verse mi artículo «Padrenuestros mayores y pequeños: fuentes antiguas y difusión románica moderna de algunos conjuros mágico-religiosos», Annali dell 'Istituto Universitario Orientale, Sezione Romanza 36 (1994) págs. 29-48.

${ }^{18}$ Los druidas celtas, por ejemplo, adoraban y tenían por símbolo una llave, que variaba en tamaño y calidad según su rango sacerdotal. Éste y muchos 
tianas, las llaves tenían valores mágico-sagrados que se han traducido en cultos ${ }^{19}$, supersticiones ${ }^{20}$ y prácticas de curación mágico-medicinal que hacen uso de ellas ${ }^{21}$. De algunos de estos cultos y supersticiones parece deducirse que es la condición de instrumento de apertura (de una puerta, pero también de la salud, de la vida, del cielo) la que confiere valores mágicos y místicos a la llave; de otros, que es su calidad metá-

otros datos al respecto los reunió Joan AMADES, Folklore de Catalunya, 3 vols. (reed. Barcelona 1982) vol. III: Costums $i$ creences págs. 630-639.

${ }^{19}$ Como el de la Virgen de las Llaves de La Seo de Urgel (Lérida), que describe Amades Catalunya pág. 638. O el de las tres llaves que colgaban de una escultura de San Pedro en la Capilla del Casto de la catedral de Oviedo, y que eran veneradas y tocadas por las jóvenes casaderas para encontrar novio, tal como afirma Constantino CABAL, Contribución al Diccionario Folklórico de Asturias: Apodo-Arriero (Oviedo 1984) pág. 129. Se conocen, además, numerosas llaves antiguas y tradicionales que tenían sus dientes en forma de cruz.

${ }^{20}$ Según Amades Catalunya págs. 638-639 y otros estudiosos, antiguamente la llave se utilizaba en procedimientos de adivinación y judiciales relacionados con los «juicios de Dios». También para guardar a los niños del mal de ojo y de las brujas se escondía una llave en su cuna. Según Rafael Salillas, La fascinación en España: Brujas, brujerías, amuletos (Madrid 1905) pág. 90, en Membrío (Cáceres) se pasa por los labios del niño inapetente la llave del sagrario de la iglesia para que vuelva a mamar. Alejandro Guichot y SIERRA, Supersticiones populares andaluzas ([1883], reed. Sevilla 1986) pág. 139, cuenta que, en Andalucía, para que a la madre se le retire la leche, no hace falta más que colgarle de la espalda una llave macho. En la República Dominicana se debe llevar colgada del cuello una llave de oro o de plata hasta la edad de siete años, según Edna Garrido DE BogGs, Folklore infantil de Santo Domingo (Madrid 1955) pág. 692. Y en Irán, a los espíritus malignos denominados djinns se les ahuyenta mediante «un cuchillo, una llave o un candado, cuyo contacto temen cervalmente», según A. RUFFAT, La superstición a través de los tiempos (Barcelona 1962) pág. 188.

${ }^{21}$ En Cataluña, según AmAdes págs. 637-638, se cura la alferecía aplicando una llave en la nuca o en un dedo del enfermo, y para prevenir el mal desde la infancia se trazan tres cruces con una llave en la frente de los niños. También para curar orzuelos y verrugas se confía en el frotamiento con una llave, costumbre que yo mismo he documentado en otros muchos lugares de España. Para curar la rabia se usan llaves de iglesias y capillas dedicadas a San Pedro, las cuales llegaron a tener tanta fama como las de Sant Pere de la Vall o las de Sant Pere d'Aransis. Entre los vascos, belgas y bretones es común también el uso de llaves como remedio o prevención contra la rabia. Las llaves colocadas en la espalda curan la rabia en determinadas regiones de Brasil, según Laura de Mello e Souza, El diablo en la tierra de Santa Cruz: Hechicería y religiosidad popular en el Brasil colonial, ed. Teresa Rodríguez MARTínez (Madrid 1993) pág. 194. Muchos más datos sobre los valores curativos en general de las llaves se pueden encontrar en Xosé Ramón MARIÑo Ferro, La medicina popular interpretada, 2 vols. (Vigo 1985-1986) vol. I págs. 171-175. Acerca del papel de las llaves en el arte, en la tecnología tradicional y en la cultura española, puede verse además Francisco GARCía GARcía, La llave: Evolución artística y valores de representación simbólica (Murcia 1992). 
lica la que justifica sus supuestos valores repelentes de enfermedades y de malos espíritus, en consonancia con los de otros objetos de hierro en muchas culturas: recuérdense ahora los ritos con clavos que también usaban los sefardíes en su aprecantar, las internacionales herraduras de la suerte, o el culto a los imanes que se practica en muchas culturas tradicionales.

«QUe El MAL DE OJo SE VAya POR ALlí O POR ALlÁ COMIENDo HUEVOS SIN SAL»

La evidente conexión formulística e ideológica entre las tres llaves (a veces «de oro») que asoman en las dos ramas del repertorio mágico y religioso hispanocristiano y sefardí se ve reforzada, además, por la coincidencia de otros elementos ideológicos y formulísticos que informan ambas ramas de textos. Por ejemplo, el mandato al mal -en la mayoría de las versiones sefardíes- para que vaya a hundirse en «la profundidad de la mar» no es sino un paralelo más de un universal motivo, muy arraigado también en la tradición hispánica, que he estudiado en otro trabajo ${ }^{22}$, por lo que bastará con contrastarlo aquí solamente con un conjuro contra el mal de ojo confesado ante la Inquisición en 1538 por María de Medina, de Guadalajara, que terminaba así:

Allá vayas, mal, de la parte del mar, donde no canta gallo ni gallina, que no pares en esta casa ni en este hogar ${ }^{23}$.

Sin embargo, mucho más inequívoco y significativo es el otro vínculo mágico-formulístico que aún puede apreciarse entre el aprecantar sefardí editado por Abraham Galanté y la tradición hispánica. Recordemos, para comprobarlo, el final del ensalmo sefardí:

Que el mal de ojo se vaya por allí o por allá comiendo huevos sin sal.

Resulta curiosísimo comprobar que esta fórmula final de la versión del ensalmo sefardí constituye un paralelo casi literal de una viejísima fórmula, documentada en la tradición españo-

${ }^{22}$ Véase Pedrosa «Pizarra».

${ }^{23}$ El ensalmo lo editó Sebastián Cirac Estopañán, Los procesos de hechicerías en la Inquisición de Castilla la Nueva (Tribunales de Toledo y Cuenca) (Madrid 1942) pág. 89. 
la de los Siglos de Oro, que, tal como la recogió Pero Vallés en su Libro de refranes de 1549, decía así:

Alla vayas mal: do comen el hueuo sin sal ${ }^{24}$.

Una versión publicada por el comendador Hernán Núñez en 1555, rezaba:

Allá vaya el mal, do comen el hueuo sin sal ${ }^{25}$.

También Gonzalo Correas incluyó varias versiones en su Vocabulario de refranes y frases proverbiales de 1627 :

Allá vaia el mal, donde komen el guevo sin sal; [o] Allá vaia el mal, do maxan los axos sin sal.

Allá vaias, mal, donde machan los axos sin sal ${ }^{26}$.

Por último, don Luis Galindo, en su monumental colección de Sentencias filosóficas y verdades morales, manuscritas entre 1660 y 1669, incluía otra versión con un curioso comentario:

Alla vayas mal,

donde comen el hueuo sin sal.

Es como execracion de los males, quiriendolos desviar y echarlos del mundo, porq[ue] en ninguna parte del y raro es, el $\mathrm{q}[\mathrm{ue}]$ coma esse manjar insulso y frigidissimo sin esta salsa ${ }^{27}$.

Es difícil hallar un sentido inequívoco y cabal a esta fórmula. La repugnancia gastronómica que inspiraba el «insulso y frigidissimo» huevo sin sal a don Luis Galindo en el siglo XVII, hasta el extremo de presentarlo como justificación de nuestra fórmula apotropaica, no constituye una explicación sólida ni coherente, pese a que tal repulsa haya seguido encontrando ecos en la tradición oral del siglo XX:

${ }^{24}$ Sigo la edición publicada en Zaragoza 1549, f. 12v.

${ }^{25}$ H. NÚÑEZ, Refranes o proverbios en romance (Salamanca 1555) f. 6r.

${ }^{26}$ G. Correas, Vocabulario, ed. L. Combet (Burdeos 1967) págs. 79-80.

${ }^{27}$ L. Galindo, Sentencias filosoficas, $i$ verdades morales, que otros llaman prouerbios o adagios castellanos, 10 vols. (Biblioteca Nacional de Madrid, Mss. B.N.M. 9772-9781) Ms. 9778, f. 224v. Se documentan además, en la misma época, versiones parecidas, como las publicadas por P. Vallés, en su Libro de refranes, f. $6 \mathrm{v}$ : «A las peñas vaya el mal» y $7 \mathrm{v}$ : «Alla vayas mal: donde te pongo buen cabeçal». 
Si un viejo te pide un beso, no se lo vayas a dar, porque los besos de viejo saben a huevo sin $\mathrm{sal}^{28}$.

Francisco Rodríguez Marín, en un interesantísimo ensayo sobre los ensalmos y conjuros en España y América, publicado en 1927, ofreció una explicación no demasiado concreta, pero sí más plausible:

Enviar lejos el mal, a paraje tan remoto de donde no le sea dado volver, es cosa frecuente en las fórmulas de los ensalmadores. Unos decían: "Allá vayas, mal, / do tiene el cuervo su nidal». Otros: «Allá vayas, mal, / donde comen el huevo sin sal» [...] Y aun en otras fórmulas se conjura el mal para que se ausente adonde mal le vaya, que no es poco apetecer: "Allá vayas, mal / do tengas piedra por cabezal» ${ }^{29}$.

En mi opinión, lo más probable es que nuestra fórmula sea, simplemente, una apretada encrucijada poética donde se combinan la intencionalidad mágica de expulsión de males, la parodia de esa misma magia (a través de la irónica metáfora de la comida de huevos sin sal), y la producción de efectos rítmicos elementales (mediante la rima «mal»/ «sal»).

Obtenemos, en fin, con estos ejemplos de parentesco poético y funcional entre todas estas formulillas supersticiosas, una referencia más completa de los modos de vida y utilización de nuestros tópicos de Las tres llaves y de Los huevos sin sal, y en general de la tradición mágico-medicinal compartida por cristianos de España y judíos de Oriente. Las lagunas documentales, así como la heterogeneidad y las tendencias a la variación, a la aglutinación y a la contaminación que las definen, impiden nuestro pronunciamiento sobre las fuentes concretas y sobre el momento y el medio de propagación precisos de ambos tópicos al oracionero sefardí de Oriente. ¿De orígenes cristianos o judíos? ¿Asimilados por los judíos de antes o por los

\footnotetext{
${ }^{28}$ Canción tradicional panameña editada en Poesía popular andina: Venezuela, Colombia, Panamá (Quito 1982) pág. 375.

${ }^{29}$ F. Rodríguez Marín, Ensalmos y conjuros de España y América: Conferencia leída en la Unión Ibero-Americana el día 17 de febrero de 1927 (Madrid 1927) pág. 17.
} 
criptojudíos de después de la expulsión? ¿Llegados de qué tradición ibérica?

Sean cuales sean las justificaciones últimas de las alusiones a estas místicas Tres llaves y a los pintorescos Huevos sin sal de nuestras oraciones y ensalmos hispanocristianos y sefardíes, lo cierto es que el análisis comparado de ambos motivos vuelve a reforzar, una vez más, la impresión de que en el repertorio mágico-religioso tradicional de los pueblos de cultura hispánica -tanto de los cristianos como de los judíos- ha pervivido y seguido manifestándose, durante siglos y hasta hoy, la antigua y resistente semilla de la pasada tradición común.

\section{RESUMEN}

Las tres llaves y Los huevos sin sal son dos fórmulas poéticas insertadas dentro de diversas oraciones y ensalmos religiosos y mágicos documentados en la tradición folclórica de España y de diversas comunidades sefardíes de Oriente. Su comparación nos ofrece una interesante oportunidad para analizar los vínculos poéticos e ideológicos entre dos tradiciones que, pese a las diferencias religiosas y distancias geográficas e históricas, han mantenido durante siglos un patrimonio oral en buena parte común.

\section{SUMMARY}

The Three Keys and The Eggs Without Salt are two poetic formulae inserted in a range of religious and magical prayers and charms registered in the folk tradition of Spain and which survive in several Sephardic oriental communities. The comparison of these two formulae provides us with an ideal opportunity to analyse the poetic and ideological links between two traditions that, despite their religious differences, geographical and historical distances, have maintained a common oral heritage throughout the past centuries. 